\title{
Floral Design Courses to Build Self-Esteem in Children Enrolled in the Community Child Care Center for Low-Income Families: Focused on the Accreditation Process of the Junior Florist Certification
}

\author{
Young Hwa Park, Suk Young Yun*, Byung Jin Choi, and Hyun Sug Choi \\ Department of Horticulture, Daegu Catholic University, Gyeongsan, 38430, Korea
}

\section{ABSTRACT}

The purpose of this study was to look into the influence of the junior florist training course on self-esteem of children in low-income families at the community child care center. Accordingly, the program was carried out by dividing 46 children into two groups from June 2 to August 30, 2017. The program was designed into 12 sessions of floral arrangement classes, followed by the certification test. For the program, this study set 11 flower forms focusing on line, surface, and mass arrangements as the basic forms of the western flower arrangements. For the certification test, this study had the participants take the junior florist course implemented by the Korea Ggotggozi Daegyeong Association. Seventy four percent of the total participants in this program acquired a Junior Florist Certificate. As a result, self-esteem of the experimental group significantly improved $(p=.000)$. By items of self-esteem, the experimental group showed significant changes in social self-esteem ( $p=.002)$, familial self-esteem $(p=.016)$, and academic self-esteem $(p=.031)$. General self-esteem did not show a statistically significant difference, but there was an improvement by $1.9 \%$, and this study found that there was a 5.4\% change on average in social, familial, and academic self-esteem. By gender, it was found that both male $(p=.003)$, and female participants $(p=.013)$ showed a significant change. By grade, there were significant changes in both the lower grades $(p=.014)$, and higher grades $(p=.003)$.

Keywords: certification test, flower forms, western flower arrangements

\section{Introduction}

Self-esteem refers to how one evaluates oneself as a valuable person and believes how competent and valuable one thinks he or she is, and it is also value judgment of oneself that appears in an individual's attitude toward oneself (Coopersmith, 1990). People with positive self-esteem think deeply about their lives, regulate and control life, share a community spirit with others in the society and thereby share love with them. Self-esteem has a significant effect on the behavioral standards of humans, and it is formed, grown and developed through individual learning or experience along with interpersonal relations, school, relationship with the society, and interaction with the surroundings. Thus, not only interaction with friends or teachers in school life but also meaningful respect for others, acceptance, and encouragement can be important factors in forming children's self-esteem (Song, 2008).

The low-income bracket legally refers to those with the bottom $9 \%$ income. In general, it refers to the bottom $19 \%$, in which the bottom $9 \%$ is referred to as the destitute poor. The low-income bracket by law refers to basic living security recipients and the second-lowest income bracket that are eligible recipients according to the National Basic Living Security Act, and families selected as those to be protected by the Mother and Fatherless Child Welfare Act.

Received: June 18, 2019, Revised: July 15, 2019, Accepted: August 7, 2019

First author: Young Hwa Park, durep@naver.com, (B) https://orcid.org/0000-0001-8232-0742

*Corresponding author: Suk Young Yun, yune1004@cu.ac.kr, (10) https://orcid.org/0000-0002-5862-0021 
Compared to children in ordinary families, children in low-income families have lower self-esteem due to the negative views of others (Kim and Hwang, 1998; Seo et al., 2013), and children who perceive that the subjective poverty level is severe also show low self-esteem (Kim, 2006). Self-esteem affects children's psychological problems, and children with lower self-esteem tend to feel more psychologically depressed and are likely to show antisocial behaviors, whereas those with higher self-esteem show less problem behavior (Jang, 2002).

Regional centers for children are facilities mostly used by children in the vulnerable social group and low-income families, and they provide comprehensive child welfare services for healthy physical and mental growth of children with the purpose of sound growth and development of children in the community that need care (Child Welfare Act, Article 52-8). Various approaches have been made to solve the problems of children in low-income families, with specific focus on their self-esteem. Kang (2004) claimed that it is necessary to operate a program to promote self-esteem as an emotional support program to give hope for children in low-income families and provide positive motivation. Various programs are studied and presented to promote self-esteem of children in low-income families, such as dramatherapy, tea ceremony, meditation, art therapy and creativity (Ahn, 2013; Ha and Nam, 2011; Kim, 2012; Lee and Son, 2011).

Many studies proved that flower arrangement is helpful in not only improving cognitive skills but also maintaining physical balance, utilizing and improving human creativity and expressivity, and bringing emotional development. It is also effective in bringing positive emotional changes that improve emotions like compulsion, depression, anxiety, paranoia and anger, while also promoting self-esteem (Lee et al., 1998; Lee et al., 2012; Son and Lee, 1997; Son et al., 2013; Tak, 2004). Furthermore, obtaining certification makes one feel proud and highly confident, increases self-efficacy and is also significantly correlated to major and career (Song, 2012; Park, 2013), while also having a positive effect on learning motivation (Jang, 2012). In this perspective, the flower arrangement course to obtain certification among horticultural programs is expected to be effective as a program that promotes emotional stability and self-esteem of children in low-income families, and thus such effects will be examined in this study. Certificates and licenses related to floral design include state registered certifications such as Craftsman Floral Design and Engineer Floral Design and a private certificate issued by an association such as the Florist Certification registered as a private license by the competent ministry. There are studies proving that floral design programs are effective for space perception and agility (Park et al., 2018), but there is insufficient research on floral design programs for children.

This study carried out a private junior florist certificate course, which is easy for children to obtain, and examined the effects of the course on self-esteem of children in low-income families using a regional center for children.

\section{Research Methods}

\section{Subjects}

The subjects are 23 children in low-income families living in D city and using a regional center for children, who also participated in the junior florist certificate course and entered for the certification test. There were 13 male and 10 female subjects, and 11 of them were in the lower grades and 12 were in higher grades of elementary school.

\section{Research tools}

\section{Experimental design}

This study is conducted to determine the effects of the junior florist flower form education and junior florist certificate course through the certification test on children's self-esteem. Self-esteem of the experimental group was measured before and after the florist certificate course. The experimental group carried out horticultural activities focused on floral design that applied 11 flower forms in flower arrangement.

\section{Junior florist course}

This study is conducted to determine the effects of the junior florist course on self-esteem of elementary school students in low-income families using a regional center for 
children and improve their self-esteem by providing them with an opportunity to obtain the junior florist certificate. The program is the basic type of Western flower arrangement using 11 flower forms focused on the line, surface and mass arrangement. The flower forms applied to the program are based on the textbooks of flower design (Kim et al., 2007) and Craftsman Floral Design Practice (Jang and Noh, 2017) as references. Line arrangement used the vertical style, horizontal style, L style, and crescent style; surface arrangement used the triangular style; and mass arrangement used the spray style, dome style, and round style designs. In addition, there was also training about table decorating wreath, bouquet and flower basket (Table 1). In each session we provided the order of flower arrangement according to flower form and horticultural design theory as the lesson plan. Session 1 is about the dome style, which presented the concept of space and symmetry, teaching children the basics of the horticultural design theory such as how to soak the floral foam in water and cut the stems. Session 2 is about wreath, which presented the concept of circle and balance, teaching how to remove thorns from the stems using a thorn remover. Session 3 is about the horizontal style (line arrangement), which presented the concept of symmetry and balance, teaching the horticultural design theory to avoid redundancies, crossing and overcrowding when arranging flower and leaf materials. Session 4 is about the round style (mass arrangement), which presented the concept of circle and angle, explaining how to water such as underwater cutting and hot water treatment. Session 5 is about the L style (line arrangement), which presented the concept of asymmetry and imbalance as well as the right angle. For the horticultural design theory, children learned about the concepts and types of line flower, form flower, mass flower, and filler flower according to morphological classification.

Session 6 is about bouquet (mass arrangement), which had children hold the stems spirally and wrap them up using felt and explained the concept of spiral bouquet as the horticultural design theory. Session 7 is about the triangular style (surface arrangement), which explained how to arrange flowers in this style, and taught children the characteristics of various types of the triangular style such as right triangle style, acute triangle style, and asymmetric triangle style. The children also learned about types of stems as the horticultural design theory. Session 8 is about the vertical style (line arrangement), which is a flower form that laid more stress on height than width. As the horticultural design theory, this session explained how to dry the flowers. Session 9 is about the spray style, which had the children arrange flowers as if the bouquet is laid on the vase and decorate it with a ribbon afterwards. They learned about the basic structure of flowers as the horticultural design theory. Session 10 is about the crescent style (line arrangement) with emphasis on the beauty of curves, which had the children form curves by inserting wire No. 20 in between 'Equisetum hyemale'. The session also taught about the types and uses of wires as the horticultural design theory. Session 11 is about flower basket (mass arrangement), having the children make flower baskets that are frequently used in daily life. They were to arrange flowers with all stems toward the center, and this session also explained about pressed flowers and how to make them. Session 12 is a wrap-up of the entire course that summarizes all the sessions for the written test, and had the children arrange flowers in the round style and spray style to prepare for the practical test. They were to finish that within 40 minutes, just like the actual time of the test. In Session 13, the children were to enter for the written test and practical test as the junior florist certificate course by Korea Ggotggozi Daegyeong Association.

\section{Program implementation}

This study implemented the program once a week every Wednesday from June 7 to August 30, 2017, with the guidance of one main therapist with Welfare Horticultural Therapist Registered certification (accredited by Korean Horticultural Therapy \& Wellbeing Association) and three assistant therapists using six rectangular tables in a $39.6 \mathrm{~m}^{2}$ room at the center. The experimental group is comprised of two teams based on the time in which the children visit the center, with 12 children in Team A and 11 in Team B. Total 13 sessions were carried out, each of which lasted 60 minutes. The key points of flower forms from the previous class are reviewed every session, and the materials and flower forms to be used on that day's flower arrangement are introduced to the children. After the flower ar- 
Table 1. Training program for florist certification

\begin{tabular}{|c|c|c|c|}
\hline Session & Program & Plants & Training content \\
\hline 1 & Dome style & $\begin{array}{l}\text { Rosa hybrida } \\
\text { Eustoma grandiflorum } \\
\text { Limonium latifolium } \\
\text { Asclepias tuberosa }\end{array}$ & $\begin{array}{l}\text { Floral foam method } \\
\text { Stem cutting }\end{array}$ \\
\hline 2 & Wreath & $\begin{array}{l}\text { Rosa hybrida } \\
\text { Oxypetalum Caeruleum } \\
\text { Dianthus caryophyllus } \\
\text { Limonium sinuatum } \\
\text { Eustoma grandiflorum }\end{array}$ & Use of rose thorn remover \\
\hline 3 & Horizontal style & $\begin{array}{l}\text { Celosia cristata } \\
\text { Eustoma grandiflorum } \\
\text { Solidaster luteus } \\
\text { Callistephus chinensis }\end{array}$ & Material theorem \\
\hline 4 & Round style & $\begin{array}{l}\text { Rosa hybrida } \\
\text { Dianthus caryophyllus } \\
\text { Dianthus chinensis } \\
\text { Hypericum inodorum }\end{array}$ & Watering (direct method) \\
\hline 5 & L style & $\begin{array}{l}\text { Dianthus caryophyllus } \\
\text { Phormium tenax } \\
\text { Aster pilosus }\end{array}$ & Line, form, mass, filler flower \\
\hline 6 & Bouquet & $\begin{array}{l}\text { Rosa hybrida } \\
\text { Eustoma grandiflorum } \\
\text { Hypericum inodorum } \\
\text { Gypsophila elegans } \\
\text { Chrysanthemum morifolium }\end{array}$ & Spiral bouquet \\
\hline 7 & Triangular style & $\begin{array}{l}\text { Phlox divaricata } \\
\text { Rosa hybrida } \\
\text { Chrysanthemum morifolium } \\
\text { Limonium sinuatum }\end{array}$ & Type of stem \\
\hline 8 & Vertical style & $\begin{array}{l}\text { Gladiolus grandavensis } \\
\text { Eustoma grandiflorum } \\
\text { Aster tataricus }\end{array}$ & Drying method \\
\hline 9 & Spray style & $\begin{array}{l}\text { Rosa hybrida } \\
\text { Gypsophila elegans }\end{array}$ & The basic structure of a flower \\
\hline 10 & Crescent style & $\begin{array}{l}\text { Equisetum hyemale } \\
\text { Rosa hybrida } \\
\text { Eustoma grandiflorum } \\
\text { Solidaster luteus }\end{array}$ & Types and uses of wire \\
\hline 11 & Flower basket & $\begin{array}{l}\text { Rosa hybrida } \\
\text { Gentiana scabra } \\
\text { Aster spp. } \\
\text { Euphorbia marginata }\end{array}$ & Principle of consolidation \\
\hline 12 & $\begin{array}{l}\text { Practical test preparation: Dome style, } \\
\text { Spray style }\end{array}$ & $\begin{array}{l}\text { Rosa hybrida } \\
\text { Gentiana scabra } \\
\text { Gomphrena globosa } \\
\text { Solidaster luteus }\end{array}$ & \\
\hline 13 & A certificate examination & & \\
\hline
\end{tabular}


rangement in the order of flower forms, the children wrap up the session by presenting their thoughts and reviews about the course.

\section{Evaluation tool and analysis method}

\section{Self-esteem scale}

The self-esteem scale developed by Choi and Jeon (1993) was used to rate the children's self-esteem level. This scale is developed for children that can give an overall evaluation of themselves and rate self-esteem in various domains in which children are involved (school, peers, studies, home) compared to self-esteem in a single domain. It has four subordinate items such as general self-esteem, social self-esteem, familial self-esteem, and academic self-esteem. There are total 32 items: six items in general self-esteem, nine items in social self-esteem, nine items in familial self-esteem and eight items in academic self-esteem. Positive items are rated as 5 points for strongly agree, 4 points for agree, 3 points for neutral, 2 points for disagree, and 1 point for strongly disagree, and negative items are rated in reverse. Cronbach's $\alpha$ (reliability) of the questionnaire is .77, and Cronbach's $\alpha$ in this study was .89 .

\section{Analysis method}

The data collected in this study is statistically analyzed using IBM SPSS Statistics 19.0 program. Pretest-posttest changes within the experimental group were analyzed using a paired sample t-test, which was also used to analyze by gender and grade for comparison according to subjects' characteristics.

\section{Results and Discussion}

\section{Pretest and posttest within the group}

\section{Changes in self-esteem}

Table 2 shows the results of analyzing the effect of the junior florist course on self-esteem of the experimental group. The self-esteem test was conducted only on the experimental group that participated in flower arrangement, and the mean score showed a significant change from 115.8 to 121.2 points after the course $(p=.000)$.

By subordinate item of self-esteem, general self-esteem did not show a significant change from 22.6 to 23.0 points after the course $(p=.318)$, but social self-esteem showed a significant change from 31.9 to 33.5 points after the course $(p=.002)$. Familial self-esteem also showed a significant change from 36.6 to 38.6 points after the course $(p=.016)$, and academic self-esteem showed a significant change from 24.7 to 26.1 points $(p=.031)$.

This result is consistent with other studies claiming that horticultural activities using flower arrangement are effective for self-esteem and school adaptation (Jeong and Lee 2009; Kim, 2016; Son et al., 2013), and that they have positive effects on children's self-esteem and peer relations (Seo et al., 2013).

\section{Comparison by gender}

Table 3 shows the results of examining the difference in the changes of the experimental group's self-esteem by gender. The male subjects showed a significant change in the mean score of self-esteem from 112.8 to 119.0 points after the course $(p=.003)$, and the female subjects also

Table 2. Changes in self-esteem scores after junior florist training course

\begin{tabular}{|c|c|c|c|c|c|}
\hline \multirow{2}{*}{ Item } & \multicolumn{2}{|c|}{ Pre-test } & \multicolumn{2}{|c|}{ Post-test } & \multirow{2}{*}{$p$} \\
\hline & M & SD & M & $\mathrm{SD}$ & \\
\hline General self-esteem & 22.6 & 3.4 & 23.0 & 3.4 & $.318^{\mathrm{NS}}$ \\
\hline Social self-esteem & 31.9 & 4.4 & 33.5 & 4.6 & $.002^{* *}$ \\
\hline Familial self-esteem & 36.6 & 6.4 & 38.6 & 5.7 & $.016^{*}$ \\
\hline Academic self-esteem & 24.7 & 4.6 & 26.1 & 5.5 & $.031^{*}$ \\
\hline Total & 115.8 & 15.1 & 121.2 & 14.8 & $.000^{* * *}$ \\
\hline
\end{tabular}

${ }^{\text {NS Non-significant, }}{ }^{*} p<.05,{ }^{* *} p<.01,{ }^{* * *} p<.001$ by paired t-test. 
Table 3. Gender differences in self-esteem scores before and after junior florist training course

\begin{tabular}{|c|c|c|c|c|c|c|}
\hline \multirow{2}{*}{ Gender } & \multirow{2}{*}{ Item } & \multicolumn{2}{|c|}{ Pre-test } & \multicolumn{2}{|c|}{ Post-test } & \multirow{2}{*}{$p$} \\
\hline & & M & SD & M & SD & \\
\hline \multirow[t]{5}{*}{ Male } & General self-esteem & 21.7 & 2.4 & 22.7 & 2.8 & $.090^{\mathrm{NS}}$ \\
\hline & Social self-esteem & 31.1 & 3.2 & 33.0 & 4.3 & $.018^{*}$ \\
\hline & Familial self-esteem & 36.0 & 5.7 & 39.2 & 4.9 & $.003^{* *}$ \\
\hline & Academic self-esteem & 24.0 & 3.9 & 24.1 & 4.3 & $.891^{\mathrm{NS}}$ \\
\hline & Total & 112.8 & 11.7 & 119.0 & 10.9 & $.003^{* *}$ \\
\hline \multirow[t]{5}{*}{ Female } & General self-esteem & 23.8 & 4.3 & 23.5 & 4.1 & $.647^{\mathrm{NS}}$ \\
\hline & Social self-esteem & 32.9 & 5.6 & 34.1 & 5.1 & $.066^{\mathrm{NS}}$ \\
\hline & Familial self-esteem & 37.3 & 7.4 & 37.7 & 6.7 & $.747^{\mathrm{NS}}$ \\
\hline & Academic self-esteem & 25.7 & 5.4 & 28.8 & 6.0 & $.012^{*}$ \\
\hline & Total & 119.7 & 18.6 & 124.1 & 19.1 & $.013^{*}$ \\
\hline
\end{tabular}

${ }^{\mathrm{NS}}$ Non-significant, ${ }^{*} p<.05,{ }^{* *} p<.01$ by paired t-test.

showed a significant change from 119.7 to $124.1(p=.013)$, indicating that there were significant changes in both male and female subjects. As for changes among the male subjects by item, general self-esteem did not show a significant change from 21.7 to 22.7 points after the course $(p=.090)$, but social self-esteem showed a significant change from 31.1 to 33.0 points $(p=.018)$. Familial self-esteem also showed a significant change from 36.0 to 39.2 points $(p=.003)$, and academic self-esteem did not show a statistically significant change although the mean score increased from 24.0 to 24.1 points $(p=.891)$.

As for changes among the female subjects by item, the mean score of general self-esteem changed from 23.8 to 23.5 points after the course $(p=.647)$, social self-esteem from 32.9 to 34.1 points $(p=.066)$, and familial self-esteem from 37.3 to 37.7 points $(p=.003)$, but there was no significant change. Only academic self-esteem showed a significant change from 25.7 to 28.8 points $(p=.012)$.

Although there are no previous studies applying only flower arrangement, the result of this study is similar to the one claiming that there was no significant difference between male and female in terms of horticultural activities including flower arrangement (Song, 2008). There was a slight difference by item, but this study showed significant changes overall in both male and female subjects. In particular, the male subjects showed a significant effect in social and familial self-esteem, showing that their confidence appeared in interpersonal relations. Moreover, the female sub- jects had stronger will to learn and take the certification test than the male subjects, thereby showing a significant effect in academic self-esteem.

\section{Comparison by grade}

Table 4 shows the results of examining the difference in the changes of the experimental group's self-esteem by grade (higher and lower grades). The mean score of self-esteem of the lower grades increased from 113.4 to 118.6 points after the course, showing a statistically significant change ( $p=.014)$, and that of the higher grades also increased from 118.0 to 123.6 points, showing a significant change ( $p=.003)$.

As for changes among the lower grades by item, general self-esteem increased from 22.4 to 23.0 points after the course $(p=.351)$, and social self-esteem increased from 31.2 to 32.7 points $(p=.090)$. Academic self-esteem did not show a significant effect from 24.5 to 24.8 points $(p=.664)$, and familial self-esteem showed a statistically significant change from 35.3 to 38.1 points ( $p=.024$ ).

As for changes among the higher grades by item, general self-esteem increased from 22.8 to 23.1 points but did not show a statistically significant change $(p=.674)$, whereas social self-esteem showed a significant change from 32.5 to 34.1 points $(p=.008)$. Familial self-esteem increased from 37.7 to 39.0 points but did not show a significant change ( $p=.266$ ), while academic self-esteem showed a significant change from 25.0 to 27.3 points $(p=.017)$. 
Table 4. Grade differences in self-esteem scores before and after junior florist training course

\begin{tabular}{|c|c|c|c|c|c|c|}
\hline \multirow{2}{*}{ Grade } & \multirow{2}{*}{ Item } & \multicolumn{2}{|c|}{ Pre-test } & \multicolumn{2}{|c|}{ Post-test } & \multirow{2}{*}{$p$} \\
\hline & & M & SD & M & SD & \\
\hline \multirow{5}{*}{$\begin{array}{c}\text { Lower } \\
\text { (1st-3rd) }\end{array}$} & General self-esteem & 22.4 & 3.6 & 23.0 & 3.3 & $.351^{\mathrm{NS}}$ \\
\hline & Social self-esteem & 31.2 & 4.6 & 32.7 & 5.0 & $.090^{\mathrm{NS}}$ \\
\hline & Familial self-esteem & 35.3 & 5.9 & 38.1 & 5.1 & $.024^{*}$ \\
\hline & Academic self-esteem & 24.5 & 5.4 & 24.8 & 6.7 & $.664^{\mathrm{NS}}$ \\
\hline & Total & 113.4 & 17.2 & 118.6 & 15.7 & $.014^{*}$ \\
\hline \multirow{5}{*}{$\begin{array}{c}\text { Upper } \\
\text { (4th-6th) }\end{array}$} & General self-esteem & 22.8 & 3.4 & 23.1 & 3.6 & $.674^{\mathrm{NS}}$ \\
\hline & Social self-esteem & 32.5 & 4.2 & 34.1 & 4.3 & $.008^{* *}$ \\
\hline & Familial self-esteem & 37.7 & 6.9 & 39.0 & 6.3 & $.266^{\mathrm{NS}}$ \\
\hline & Academic self-esteem & 25.0 & 4.0 & 27.3 & 4.1 & $.017^{*}$ \\
\hline & Total & 118.0 & 13.3 & 123.6 & 14.3 & $.003^{* *}$ \\
\hline
\end{tabular}

${ }^{\mathrm{NS}}$ Non-significant, ${ }^{*} p<.05,{ }^{* *} p<.01,{ }^{* * *} p<.001$ by paired t-test.

By grade of the experimental group, the lower grades showed a significant difference within $5 \%$ only in familial self-esteem, and the higher grades showed a significant difference within $5 \%$ in social self-esteem and academic self-esteem. In total mean score of self-esteem, both the lower and higher grades showed a statistically significant change. This result is similar to the results that horticultural activities including flower arrangement significantly changed self-esteem and trust (Jeong and Lee, 2009; Shin, 2010; Song, 2008). Since the lower grades have greater familial correlation than the higher grades, building a positive relationship at home may have served as a factor that improved fanilial self-esteem. As for the significant difference in social and academic self-esteem of the higher grades, social self-esteem is improved because the subjects gain confidence through their completed works and express this confidence at home and school (Jeong, 2009), and academic self-esteem is improved since the subjects learn about the spatial concept and design theories through the course.

\section{Junior florist certificate test results}

The junior florist certificate test was conducted after Session 12, and the children were to enter for the junior florist certificate course performed by Korea Ggotggozi Daegyeong Association. The floral design course gives certification by evaluating an individual's knowledge and skills about florists according to certain criteria, and the certificate test is divided into the written test and the practical test. It was applied equally as the Craftsman Floral Design test conducted by the Human Resources Development Service of Korea, and the written test was conducted for 40 minutes with 20 questions in flower materials and morphology, maintaining and managing flower quality, floral decorations, and floral design. The practical test was for 40 minutes with the topic of "arranging a table centerpiece with the flower form you are most confident to work with," requiring the children to use at least $70 \%$ of the materials. To pass, they must earn at least 60 out of 100 points in both the written and practical tests. Twenty three children entered for the test, and 17 of them scored at least 60 points in the written and practical tests, showing a $74 \%$ ratio of successful applicants, who were given a junior florist certificate (Table 5). Eight out of 13 male subjects (62\%) and nine out of 10 female subjects (90\%) passed the test, and by grade, eight out of 11 lower-grade children $(73 \%)$ and nine out of 12 higher-grade children (75\%) passed the test. According to the research findings that children with many chances to encounter flowers and plants show high preference and interest (Kwack et al., 2012), girls have more opportunities to encounter flowers and showed higher preference. In this program, girls showed a stronger will to learn and obtain certification, thereby showing a higher rate of success. 
Table 5. Junior florist certificate test results of the participants

\begin{tabular}{|c|c|c|c|c|c|c|c|}
\hline No. & Theoretical score & Practical score & Result & No. & Theoretical score & Practical score & Result \\
\hline 1 & 45 & 80 & - & 13 & 100 & 90 & Pass \\
\hline 2 & 100 & 95 & Pass & 14 & 60 & 80 & Pass \\
\hline 3 & 100 & 95 & Pass & 15 & 45 & 75 & - \\
\hline 4 & 80 & 92 & Pass & 16 & 40 & 75 & - \\
\hline 5 & 60 & 75 & Pass & 17 & 55 & 80 & - \\
\hline 6 & 100 & 95 & Pass & 18 & 70 & 90 & Pass \\
\hline 7 & 95 & 90 & Pass & 19 & 100 & 92 & Pass \\
\hline 8 & 95 & 95 & Pass & 20 & 70 & 85 & Pass \\
\hline 9 & 60 & 85 & Pass & 21 & 35 & 75 & - \\
\hline 10 & 80 & 90 & Pass & 22 & 90 & 85 & Pass \\
\hline 11 & 60 & 85 & Pass & 23 & 35 & 80 & - \\
\hline 12 & 95 & 85 & Pass & & & & \\
\hline
\end{tabular}

\section{Conclusion}

To determine the effects of the junior florist certificate course on self-esteem of children going to a regional center for children and provide an opportunity to obtain certification as a self-esteem promoting program, we divided 46 children using a regional center for children in D city into two groups and carried out the program in 12 sessions from June 2 to August 30, 2017. This study has limitations in that only the experimental group is set without comparing with the control group, and thus changes in self-esteem cannot be compared to the control group. However, by comparing the subjects before and after the certificate course, this study is to determine the effects of the floral design certification course on the changes of children's self-esteem.

The total mean score of self-esteem in the experimental group that participated in flower arrangement showed a significant change from 115.8 to 121.2 points $(p=.000)$. All items of self-esteem except general self-esteem showed a significant change, such as social self-esteem $(p=.002)$, familial self-esteem $(p=.016)$, and academic self-esteem $(p=.031)$. General self-esteem did not show a statistically significant result but showed a $1.9 \%$ increase rate, and social self-esteem $5.1 \%$, familial self-esteem $5.5 \%$, and academic self-esteem $5.6 \%$.

As a result of statistically examining the differences by gender, there were significant changes in both male $(p=.003)$ and female subjects $(p=.013)$. By item, male subjects showed a significant change in social self-esteem $(p=.018)$ and $\mathrm{v}$ self-esteem $(p=.003)$, while female subjects showed a significant change in academic self-esteem $(p=.012)$. According to the grades, there were significant changes in both lower grades $(p=.014)$ and higher grades $(p=.003)$. By item, the lower grades showed a significant change in familial self-esteem $(p=.024)$, while the higher grades showed a significant change in social self-esteem $(p=.008)$ and academic self-esteem $(p=.017)$.

Therefore, students that participated in the junior florist course showed positive changes in self-esteem. This result was a positive motivation for them to complete their works and obtain certification through the junior florist certificate course, which affected confidence and positive emotions and thereby improving self-esteem. Although this study only applied the floral design certification, it is also worth applying various other certificate courses using plants according to the therapeutic purposes for each subject.

\section{References}

Ahn, J.H. 2013. A study on drama therapy for children in low-income families: Focusing on self-expression ability and self-esteem. Master's thesis, Dongduk Women's University, Seoul, Korea.

Choi, B.G. and G.Y. Jeon. 1993. A study on the develop- 
ment of the self-esteem inventory (I). J. Korean Home Econ. Assoc. 31(2):41-54.

Coopersmith, S. 1990. The antecedents of self-esteem. Palo Alto, CA: Consulting Psychologists Press.

Ha, M.Y. and S.K. Nam. 2011. The effects of group art therapy program on the self-esteem and sociability of children from low-income families. Korean J. Arts Ther. 11(2):219-245.

Jang, E.O. and S.B. Noh. 2017. Craftsman floral design: Actual. Seoul, Korea: Soopool Media.

Jang, S.J. 2012. A study on the effect of IT certification classes for elementary school students on learning motive. Master's thesis, Yonsei University, Seoul, Korea.

Jang, Y.S. 2002. A study on the relationship among technical high school students' self-respect, level of stress and delinquent behaviors. Master's thesis, Yonsei University, Seoul, Korea.

Jeong, A.G. 2009. Effect of horticultural activities on self-esteem and sociality for children of low-income groups. Master's thesis, Chungnam NatIonal University, Daejeon, Korea.

Jeong, Y.O. and J.H. Lee. 2009. The influence of in-classroom horticultural activities on the reduction of elementary school students aggression and stress. J. Korean Pract. Arts Educ. 22(4):151-172.

Kang, Y.J. 2004. The study on the elementary school children's self esteem and depression in poverty family. Nat. Sci. [Daejeon University] 15(1):15-26.

Kim, J.H. 2012. Basic research on integrated program for tea ceremony and meditation. J. Tea Cult. Ind. Stud. 21:91-122.

Kim, J.H., J.Y. Kim, and S.J. Ahn. 2007. Easily learn flower design. Seoul, Korea: Flowernews.

Kim, K.H. 2006. Process analysis of poverty influences on academic attainment of children. Korean J. Soc. Welf. 58(4):265-289.

Kim, K.H. and H.J. Hwang. 1998. Children's emotional and behavioral problems and their parents' acceptance and rejection in low income families. Korean $\mathrm{J}$. Psychol: Dev. 11(1):12-26.

Kim, T.G. 2016. Effect of the horticultural activity programs on the self-esteem and adaptability of elementary in the elementary school students. Master's thesis, Gyeongnam National University of Science and Technology, Jinju, Korea.

Kwack, H.R., E.J. Jang, and H.Y. Lee. 2012. Analysis of characteristics and preference of horticultural activities and plants of multicultural children. J. Korean Soc. People Plants Environ. 15(5):337-348.

Lee, J.M., K.C. Son, and E.H. Koh. 1998. Practical application of flower \& art design as horticultural therapy. Proceedings of first symposium of Korean horticultural therapy association. Seoul, Korea: Seowon Press.

Lee, S.B. and J.H. Son. 2011. Effect of community-based creativity-enhancing program on creativity, self-esteem and physical self-efficiency of children from low-income families. Korean J. Child Educ. 20(3):33-50.

Lee, S.S., S.A. Park, O.Y. Kwon, J.E. Song, and K.C. Son. 2012. Measuring range of motion and muscle activation of flower arrangement tasks and application for improving upper limb function. Korean J. Hortic. Sci. Technol. 30(4):449-462.

Park, S.O. 2013. A study on how the acquisition of certification affects the rise in specialized high school students' academic self-efficacy. Master's thesis, Chonnam National University, Gwangju, Korea.

Park, Y.H., S.Y. Yun, H.S. Choi, and B.J. Choi. 2018 The effects of junior florist training course on the spatial perception ability and hand dexterity of low-income children of local child center. J. People Plants Environ. 21(5):393-401. https://doi.org/10.11628/ksppe.2018.21.5.393

Seo, R.M., M.J. Lee, and W. Oh. 2013. Effects of after-school horticultural activities on the depression and self-esteem of children from low-income families. J. Korean Soc. People Plants Environ. 16(5):261-266. https://doi.org/10.11628/ksppe.2013.16.5.261

Shin, Y.S. 2010. Effect of after school horticultural activity on the sociality and self-esteem of children from the low income families. J. Korean Soc. People Plants Environ. 13(6):33-39.

Son, K.C. and J.S. Lee. 1997. Effects of indoor plants on the changes of human brain electoencephalography(EEG). Proc. Korean Soc. Hortic. Sci. 15(1):653-654. 
Son, M.L., E.J. Jang, and C.H. Park. 2013. Effect of flower decoration horticulture program on emotional stabilization and stress of woman high school students. J. Korean Soc. People Plants Environ. 16(3):119-124.

Song, D.Y. 2008. Effect of the classroom horticultural program on elementary school student's self-esteem and peer-relationships. Master's thesis, Cheongju National University of Education, Korea.
Song, G.I. 2012. The effect of cooking technician certification role on self-efficacy, self-esteem and career decision. Master's thesis, Nambu University, Gwangju, Korea.

Tak, Y.S. 2004. The effect of horticultural therapy using the flower arrangement in center: Terminal cancer patients. Master's thesis, Honam University, Gwangju, Korea. 